\title{
Is It All About Retribution? The Flexibility of Punishment Goals
}

\author{
Mathias Twardawski ${ }^{1,2}$ (D) Karen T. Y. Tang ${ }^{3,4} \cdot$ Benjamin E. Hilbig $^{2}$
}

Published online: 12 March 2020

(c) The Author(s) 2020

\begin{abstract}
Current literature suggests that laypeople's punishment is primarily driven by retributive reasons (i.e., to give offender their just deserts) rather than utilitarian purposes such as special prevention (i.e., to prevent recidivism of the offender) or general prevention (i.e., to prevent the imitation of the crime by others). One explanation for this may be that individuals tend to focus on salient cues while ignoring others when making a decision and critically, generally pay relatively little attention to secondary or long-term effects of their decision-making. This suggests that people's punishment goals may be subject to the information salient about the crime situation. Specifically, individuals may only pursue utilitarian goals with their punishment, if aspects related to such long-term consequences of punishment are salient (such as information about the offender or the broad circumstances surrounding the crime). To examine this, we manipulated the salience of different aspects in a scenario describing a crime. In two preregistered experiments, participants were asked to choose from (Experiment $1, N=291$ ) or rate the appropriateness of (Experiment 2, $N=366$ ) different reactions to the crime; these reactions were pretested for the degree to which they served each of the punishment goals: retribution, special prevention, and general prevention. As hypothesized, we found that participants' punishment goals were associated with the salience of specific aspects of the scenario describing the crime situation. This extends on research suggesting that laypeople's punishment goals are malleable and may depend on the research design employed by a particular study.
\end{abstract}

Keywords Punishment goals · Retribution · Utilitarianism · Information salience

Mathias Twardawski

m.twardawski@1mu.de

1 Ludwig-Maximilians-Universität München, Munich, Germany

2 University of Koblenz-Landau, Landau, Germany

3 Dalhousie University, Halifax, Canada

4 University of Calgary, Calgary, Canada 


\section{Introduction}

In the last two decades, a growing body of research has been dedicated to investigating the goals of individuals' third-party punishment behavior, that is, people engaging in punishment who are not personally affected by the wrongdoing (Fehr \& Fischbacher, 2004). This research is inextricably associated with the philosophical works of Immanuel Kant and Jeremy Bentham that provide disparate approaches in justifying the intrinsically destructive act of punishment. According to Kant (1952), the primary reason for punishment of criminal offenders is to rebalance the moral wrong that has been committed by the offense. This punishment philosophy is referred to as retribution. A retributive sentence is proportionate to the (intended) harm of the specific wrong committed. Thus, according to Kant, a legitimate sentencing lets the 'punishment fit the crime.' As punishment in this regard is only concerned with the past misbehavior, it is construed as a backward-oriented punishment (Goodwin \& Gromet, 2014; Keller, Oswald, Stucki, \& Gollwitzer, 2010; Tetlock, 2002). In other words, adopting a retributive perspective necessitates one to focus on elements of the past, for instance, by determining the seriousness of the offense.

By contrast, Bentham (1962) considered the act of punishment from a more utilitarian view on people's behavior. Accordingly, the intrinsically bad act of punishment can only be seen as justified if it leads to good consequences, for example by preventing future misbehavior. As punishment in this regard is only concerned with future consequences, it is construed as a forward-oriented punishment (Goodwin \& Gromet, 2014; Keller et al., 2010; Tetlock, 2002). In other words, adopting a utilitarian principle necessitates one to attempt to predict the future, for instance, by determining a punishment's capacity to prevent transgressions in the future. Utilitarian punishment can further be differentiated into special prevention and general prevention (Goodwin \& Benforado, 2015; Keller et al., 2010; Rucker, Polifroni, Tetlock, \& Scott, 2004; Tetlock, 2002; Twardawski, Hilbig, \& Thielmann, 2020). Special preventive punishment is primarily concerned with the offenders themselves, by attempting to prevent future recidivism through rehabilitative measures or incapacitation (Keller et al., 2010), whereas general preventive punishment is primarily concerned with other members of the society that might have been informed of the offense and, therefore, may imitate the misbehavior if it goes unpunished (Goodwin \& Benforado, 2015).

Although punishment goals are not necessarily mutually exclusive and people view the satisfaction of multiple goals as an appropriate and just response to wrongdoing (Gromet \& Darley, 2009), a great body of research on laypeople's punishment goals has dealt with the question on whether there is a primary objective in punishment behavior (i.e., whether people primarily punish for retributive or utilitarian purposes). This research demonstrated an apparent consensus: Punishment, it appears, is predominantly driven by retribution (i.e., to even out the wrong that has been done) rather than special or general prevention (i.e., to prevent future crimes by the offender or others; Carlsmith, 2006; Carlsmith, Darley, $\&$ Robinson, 2002). This has led researchers to conclude that "people are intuitive 
retributivists' (Carlsmith \& Darley, 2008, p. 211; see also Carlsmith, 2006; Carlsmith et al., 2002; Giacomantonio \& Pierro, 2014; Goodwin \& Gromet, 2014; Keller et al., 2010).

Crucially, however, there is a growing body of evidence suggesting that laypeople's punishment goals are context dependent and influenced by diverse factors such as the personality of the punisher (Giacomantonio \& Pierro, 2014; Giacomantonio, Pierro, Baldner, \& Kruglanski, 2017) or specific aspects of the crime itself (e.g., the severity of the misbehavior, with more severe crimes leading to more retributive punishment; Gromet \& Darley, 2006). Furthermore, the attribution of the misbehavior also affects individuals' punishment goals (Weiner, Graham, \& Reyna, 1997); attribution of the misbehavior to a more controllable cause leads to more retributive punishment (and vice versa), whereas attribution to a more unstable cause leads to more special preventive punishment (and vice versa). This research demonstrates that laypeople's punishment is motivated by utilitarian purposes to varying degrees, depending on a variety of other factors.

\section{Information Salience and Laypeople's Punishment Goals}

In the present research, we add to this literature by investigating the influence of information salient about a crime situation on laypeople's punishment goals. The rationale of our research is based on the 'isolation effect' (McCaffery \& Baron, 2006, p. 289), suggesting that individuals tend to focus on salient cues while ignoring others and importantly, generally pay relatively little attention to secondary or long-term effects of their decision-making. Such a neglect of long-term effects of decisions has also been found in punishment behavior. For example, recent research has shown that individuals generally do not incorporate the costs of incarceration into their punishment preferences, unless information about such costs is made explicitly salient (Aharoni, Kleider-Offutt, Brosnan, \& Watzek, 2018). Given that the support for utilitarian punishment requires, by definition, a forward-oriented thinking about punishment (i.e., taking long-term effects into account), punishers may only consider pursuing such punishment goals if information related to utilitarian aspects of the crime situation is salient. In other words, so long as only aspects associated with retribution (i.e., enabling to evaluate the appropriateness of a punishment with regard to a retributive approach) are salient, it must be expected that people's punishment is mostly driven by a retributive thinking.

Indeed, some aspects of a crime situation are more relevant for a particular punishment goal than for others (Carlsmith, 2006; Keller et al., 2010). In particular, retributive punishment is associated with aspects of the crime itself (such as the magnitude of harm caused by the criminal behavior); special prevention is associated with aspects of the offender (such as the probability of recidivism); and general prevention is associated with aspects of the community the crime occurred in (such as the public awareness of the crime and sentencing). Importantly, there is also some evidence suggesting that information salience influences laypeople's punishment goals, as future-oriented punishment goals received higher support in studies in which utilitarian-related aspects of the crime situation were more salient to 
participants (Baron \& Ritov, 2009). More precisely, this research has shown that people generally ignore the probability of detection of an offense in judgments of punishment, unless when specifically instructed to consider potential negative consequences of this ignorance. Similarly, research instructing participants to focus on specific aspects of the description of a crime situation showed that altering individuals' perspective on a crime situation changes the goals they intend to achieve with their punishment (Gromet \& Darley, 2009). In this study, participants were asked to read a scenario about a crime and indicate their punishment goals. Subsequently, they were asked to re-read the same scenario, but were explicitly told to focus on a specific target of the crime situation (i.e., the offender, the victim, or the community in which the crime occurred), and then indicate their punishment goals again. As predicted, participants' punishment goals shifted depending on the target they were asked to focus on.

Taken together, it is clearly implied that if aspects other than the crime itself are salient (e.g., the offender's motives or the community in which the crime has taken place), individuals are able to incorporate this information in their decision-making and adjust their punishment to achieve other, non-retributive goals. By contrast, if people do not receive any information about associated aspects other than the crime itself (or if such utilitarian-related information is not salient to them), their punishment decision must appear primarily retributive, even if utilitarian goals may have been applicable in principle.

To test this prediction, we conducted two preregistered experiments and varied the salience of aspects of the crime situation that have been shown to be associated with three broad punishment goals: retribution, special prevention, and general prevention. Our predictions were based on research in which participants indicated that some aspects of a crime situation are more relevant for a particular punishment goal than for others: Aspects of the crime itself are most relevant for retributive punishment; aspects of the offender are most relevant for special prevention; and aspects of the community the crime occurred in are most relevant for general prevention (Carlsmith, 2006; Keller et al., 2010). Our main prediction is that in a crime situation in which all punishment goals are eligible in principle, the support for retribution, special prevention, and general prevention as goals of punishment depends on the salience of aspects of the crime itself, the offender, and the community in which the crime occurred, respectively. Specifically, we hypothesized that in such a crime situation, increasing the salience of information about the crime itself will increase the endorsement of retribution as a punishment goal; increasing the salience of information about the offender will increase the endorsement of special prevention as a punishment goal; and increasing the salience of information about the community the crime occurred in will increase the endorsement of general prevention as a punishment goal. These hypotheses were preregistered as outlined above (both preregistrations are available online on the Open Science Framework (OSF) and can be accessed via the following links: https://osf.io/v8e9t and https://osf.io/7mqp8). Additional materials (including the instructions and materials used in our preliminary studies and both experiments, along with all data and supplementary analyses) are also available on the OSF and can be accessed via the following links: https:// osf.io/dba47 and https://osf.io/hfnp8. 
We tested these hypotheses in two experiments with different online samples (recruited through the Amazon Mechanical Turk website and various other research platforms and personal contacts), different designs (between- and within-subjects manipulation of information salience), and different approaches to measure participants' punishment goals. Specifically, we used a direct endorsement measure of punishment goals, asking participants to indicate the degree to which they endorse retribution, special prevention, and general prevention as different goals of punishment in the described situation. However, past research has repeatedly revealed rather weak correlations between participants' explicit endorsement of punishment goals and their actual punishment behavior. Specifically, it appears that laypeople highly endorse all goals of punishment and generally overestimate the influence of utilitarian goals on their own punishment decisions, although their actual punishment behavior is mostly retributive (Carlsmith, 2008; Crockett, Özdemir, \& Fehr, 2014). Consequently, it is important to consider additional, less direct or explicit measures of punishment goals. We therefore additionally implemented a more indirect measure of punishment goals that provides participants with specific punishment reactions (which may serve certain goals without stating these goals explicitly) with the task of choosing from (Experiment 1) or rating the appropriateness of (Experiment 2 ) these reactions. To the extent that the reactions are known to differ on how well they serve different punishment goals, one can consider participants' behavior (i.e., choice or appropriateness rating) as an indirect measure of their punishment goals, without requiring them to introspectively predict the exact goals they may be intending to achieve. For both experiments, we report how we determined our sample size, all data exclusions (if any), manipulations, and measures (Simmons, Nelson, \& Simonsohn, 2012).

\section{Experiment 1}

In the first experiment, we asked participants to read a crime scenario describing a fictional burglary. Using a between-subjects design, this scenario either made information about the crime itself (i.e., crime focused condition), the offender (i.e., offender focused condition), or the community (i.e., community focused condition) in which the burglary occurred most salient. Participants were asked to select one of the three options to react to the situation described in the scenario. Each reaction was associated with a different punishment goal. Furthermore, they were asked to indicate the goals they would want to accomplish if presented with the chance to react to the burglary situation.

\section{Methods}

The experimental material used to test our hypotheses was pretested in two separate studies. A third preliminary study was conducted to test the general eligibility of 
the reactions in the crime situation. ${ }^{1}$ Material, data, and results of these preliminary studies can be found in detail in the supplementary material on the OSF (see above).

\section{First Preliminary Study: Testing Scenarios}

To investigate whether information salience has an impact on punishment goals, we created three different versions of a scenario describing a fictional burglary. These three versions were intended to differ in the salience of specific aspects of the crime situation, primarily the offender, the community in which the crime had taken place, and the crime itself. At the same time, the three versions were intended to be equivalent in their general content and in other variables that are known to influence individuals' punishment goals, that is, the perceived severity of the crime (Gromet \& Darley, 2006; Rucker et al., 2004) and the attribution of the misbehavior in terms of the controllability and stability of its cause (Weiner et al., 1997).

To achieve these objectives, all scenario versions consisted of two paragraphs. The first paragraph gave basic information about the crime, the offender, and the community; this was constant across all scenario versions. This paragraph read as follows:

On April 20th, a break-in took place in a male victim's home. No one was harmed in this random break-and-enter, but up to $\$ 3000$ was stolen. The community has been shaken up due to the increased rate in crime in their neighborhood recently. The male offender was caught days later. He has committed smaller crimes before, but this is the offender's first offense of this magnitude.

The second paragraph elaborated on the information already provided in the first by making specific aspects of the burglary case more salient, but, crucially, did not add any additional information to different scenarios that may have influenced the perception of the crime situation on the dimensions known to be associated with people's punishment goals as stated above (i.e., the severity of the criminal behavior and the attribution of the misbehavior). The additional information added in the second paragraph was either about the crime itself, the offender, or the community in which the crime occurred. Correspondingly, the crime focused scenario version contained further information elaborating on the crime itself (e.g., that a crowbar had been used to remove a basement window and that the burglary resulted in dozens of possessions stolen). The offender focused scenario version contained further information elaborating on the offender that committed the crime (e.g., that the offender had committed only smaller crimes in the past and that this was his first crime of this magnitude). The community focused scenario version contained further information elaborating on the community in which the crime occurred (e.g., that the incident was one of many crimes within the past months and that because of the reported increase in crime, residents began to question the safety of their community).

\footnotetext{
${ }^{1}$ To be precise, the study was run after completion of Experiments 1 and 2 given that its necessity became apparent only later.
} 
To pretest different scenario versions, we asked $N=102$ participants to rate all three versions on the described dimensions. Participants were recruited through the Amazon Mechanical Turk Web site to take part this study lasting approximately $15 \mathrm{~min}$ for $\$ 0.80$. Due to technical error with the survey program, we are not able to provide any demographic information. This study confirmed the suitability of our material (i.e., the versions were perceived as different in their focus on either the crime itself, the offender, or the community in which the crime occurred). In addition, they were rated as equivalent in terms of the severity of the offense and the attribution of the misbehavior in terms of the controllability and stability of its cause. Again, this was important to rule out that the additional information provided in each condition did not lead to different perceptions on dimensions known to be associated with people's punishment goals. Material, data, and results of this preliminary study can be found in detail in the supplementary material on the OSF.

\section{Second Preliminary Study: Testing Reactions}

As outlined above, explicit endorsement measures of people's punishment goals may have some disadvantageous in predicting actual punishment behavior (e.g., Crockett et al., 2014). Consequently, we added a more indirect measure to measure participants' punishment goals without asking them to introspectively predict the goals they may be intending to achieve. Specifically, we created several possible reactions to the burglary case. These reactions were pretested for the degree to which they served each of the punishment goals: retribution, special prevention, and general prevention. We aimed to extract three reactions (one for each punishment goal) that would primarily serve one of the goals but not the other two. Additionally, the reactions were intended to be perceived as equally severe. To pretest the reactions, we recruited $N=80$ participants through the Amazon Mechanical Turk platform to take this study lasting $10 \mathrm{~min}$ for $\$ 0.50$. In this sample, ages ranged between 21 and 87 years $(M=35.83, \mathrm{SD}=11.29)$ and $50 \%$ of participants were female. The majority of participants indicated to be of Caucasian ethnicity $(79 \%)$ and fluent in English (99\%). Participants were only eligible if they had not completed the first preliminary study. We provided participants with the definitions of the three punishment goals and asked them to rate nine reactions to the burglary on how well they achieved each goal. Thus, we were able to extract three punishment reactions that were perceived as primarily serving one of the goals but not the other two. Material, data, and results of this preliminary study can be found in detail in the supplementary material on the OSF.

\section{Third Preliminary Study: Testing Eligibility of the Reactions in the Crime Situation}

In the present research, we predicted that in a crime situation in which all punishment goals are eligible in principle, the support for different punishment goals will depend on the salience of specific aspects of the description of the crime situation. Thus, individuals should actually rate the three punishment goals as equally eligible if they received all information about the crime situation. More precisely, if participants received comprehensive information about the crime itself, the offender, and 
the community, all punishment goals (or the reactions achieving these goals) should receive comparable support.

To ensure that the crime scenario we created was correspondingly unbiased (i.e., allowed for all three punishment goals to be equally endorsed in principle), we provided $N=270$ participants with the basic information part (i.e., the first paragraph) of the scenario article used in the experiments and, additionally, all pieces of information about the crime itself, the offender, and the community (i.e., the second paragraphs, containing specific pieces of information used to increase salience in each of the experimental conditions). Participants, again, were recruited through the Amazon Mechanical Turk platform to take this 5-min study for $\$ 0.50$. In this sample, ages ranged between 22 and 76 years $(M=38.66, \mathrm{SD}=11.98)$ and $56 \%$ of participants were female. The majority of participants indicated they were of Caucasian ethnicity (72\%) and fluent in English (95\%). Participants were only eligible if they had not completed the first and second preliminary studies. Findings confirmed that, when provided with all information about the crime situation, participants supported the three punishment goals relatively equally, with only very minor differences (i.e., effects not even amounting to a small effect size). Again, material, data, and results of this preliminary study can be found in detail in the supplementary material on the OSF.

\section{Measures and Procedure}

After providing informed consent and demographic information, participants were randomly assigned to one of the three conditions: crime focused, offender focused, or community focused. All participants read a scenario describing a burglary consisting of (1) basic information that was completely identical across all conditions and (2) specific information pertaining to the experimental condition, that is, making either the crime, the offender, or the community more salient (see first preliminary study). Next, participants were asked to complete a comprehension check on what they had read. The comprehension check questions were specific to the condition (e.g., in the offender focused condition: 'Why did the offender commit the crime?'). It was imperative that participants answer these questions correctly before moving on with the experiment; they were given two attempts to complete this successfully before proceeding. Participants were then asked to respond to the two main dependent variables (i.e., the indirect reaction measure and the direct goal endorsement measure). For the indirect reaction measure, we extracted three reactions to the burglary from our second preliminary study (see above). Therefore, each reaction primarily served one of the punishment goals of interest (i.e., retribution, special prevention, and general prevention). To indirectly measure participants' punishment goals, we asked participants to imagine that they had a chance to react to the situation described in the scenario and to select one of the three possible reactions.

As the direct endorsement measure of punishment goals, we adapted nine items (three items for each punishment goal) from Orth (2003, although this research actually investigated the goals in second rather than third-party punishment) and Weiner et al. (1997). In these items, participants were asked to indicate the goals they would want to accomplish if presented with the chance to react to the burglary 
situation (e.g., 'To what extent would you like to react to decrease the likelihood of the offender from committing future crimes again?'). Each item was answered on a 7-point scale ranging from $1=$ 'not at all' to $7=$ 'completely.' For each punishment goal, the (three) answers were averaged per participant such that higher values indicate stronger endorsement of a particular punishment goal. All items can be found in the supplementary material on the OSF.

Afterward, participants answered three manipulation check questions on the extent to which the scenario they read was focused on the offender, the community in which the crime occurred, and the crime itself (e.g., 'To what extent did this passage focus on the offender?'). Furthermore, participants were asked to rate the severity of the crime ('To what extent should the offence described in the article be considered serious?'). They were also asked to indicate their attribution of the criminal behavior described in the scenario in terms of (a.) controllability ('To what extent was the offender's behavior controllable (i.e., controllable by the offender)') and (b.) stability of the cause of the criminal behavior ('To what extent is the behavior described in the article caused by stable characteristics of the offender (i.e., remains stable over time)?'; Reyna \& Weiner, 2001). All items were answered on a 7 -point scale ranging from $1=$ 'not at all' to $7=$ 'completely.' Finally, participants were asked basic questions about the content of the experiment including one item testing their attentiveness ('If you participated conscientiously, please choose the third answer option.') before they were debriefed and thanked.

\section{Sample}

We conducted a priori power analyses using $\mathrm{G}^{*}$ Power (Faul, Erdfelder, Buchner, \& Lang, 2009) for both dependent variables: the direct endorsement and the indirect reaction measure of punishment goals. A power analysis for the direct measure of punishment goals revealed the following results: To detect an effect of $f=.175$ (small to medium effect size) in a repeated measures ANOVA with a power of .80 (given $\alpha=.05$, number of groups $=3$, number of measurements $=3$, and nonsphericity correction $\epsilon=1), N=201$ participants are necessary. A power analysis for the indirect measure of punishment goals revealed the following results: To detect an effect of $w=.20$ (small to medium effect size) in a Chi-square goodness-of-fit test (contingency tables) with a power of $.80(\alpha=.05$, and $d f=2), N=241$ participants are needed.

Participants were recruited through the Amazon Mechanical Turk Web site to take this experiment lasting around $10 \mathrm{~min}$ for $\$ 0.50$. Participants of all our preliminary studies were exempt from participation. Anticipating some participants would fail the attention check at the end of the experiment, we collected data from $N=301$ participants. From these participants, $n=2$ had to be excluded due to repeated participation. ${ }^{2}$ Furthermore, $n=8$ participants had to be excluded because they answered the attention check question at the end of the experiment incorrectly,

\footnotetext{
${ }^{2}$ This was identified through completely identical answers in both an 8-digit pseudocode and the demographic data.
} 
leaving a sample of $N=291$ participants. In the final sample, ages ranged between 18 and 73 years $(M=39.36, \mathrm{SD}=12.28)$ and $53 \%$ of participants were female. The majority of participants indicated they were of Caucasian ethnicity $(85 \%)$ and fluent in English (98\%). ${ }^{3}$

\section{Results}

\section{Manipulation Checks and Control Variables}

Replicating the results of our first preliminary study, we found the manipulation to be successful. The crime focused scenario was rated as having a greater focus on the crime $(M=5.87, \mathrm{SD}=1.07)$ than on the offender $(M=4.81, \mathrm{SD}=1.47), t(98)=5.70$, $p<.001, d=0.57$, and the community $(M=3.92, \mathrm{SD}=1.45), t(98)=10.40, p<.001$, $d=1.05$. The offender focused scenario was rated as having a greater focus on the offender $(M=5.88, \mathrm{SD}=0.88)$ than on the crime $(M=4.82, \mathrm{SD}=1.29), t(96)=7.35$, $p<.001, d=0.75$, and the community $(M=4.19, \mathrm{SD}=1.38), t(96)=10.10, p<.001$, $d=1.03$. Finally, the community focused scenario was rated as having a greater focus on the community $(M=6.04, \mathrm{SD}=1.02)$ than on the crime $(M=4.56, \mathrm{SD}=1.37)$, $t(94)=9.10, p<.001, d=0.93$, and the offender $(M=3.91, \mathrm{SD}=1.40), t(94)=11.67$, $p<.001, d=1.20$. We submitted participants' ratings of the focus of the scenarios to a mixed-design ANOVA with scenario version (crime focused, offender focused, and community focused) as the between-subjects factor and the focus rating (focus on the crime, offender, and community) as the within-subjects factor. In line with our first preliminary study, the overall ANOVA indicated a significant main effect of the focus to be rated, $F(2,576)=6.92, p=.001, \hat{\eta}_{\mathrm{G}}^{2}=.01$, with a slightly greater focus on the crime across all scenarios. Most importantly, the interaction between the scenario version and the focus to be rated was significant, $F(4,576)=92.72$, $p<.001, \hat{\eta}_{\mathrm{G}}^{2}=.28$.

Concerning the control variables, the three scenarios were rated differently in terms of both severity and stability of the cause of the crime, which is in contrast to the results of our first preliminary study. The community focused scenario was rated as more severe $(M=5.99, \mathrm{SD}=1.12)$ than the offender focused version $(M=5.58$, $\mathrm{SD}=1.10), t(189.74)=2.58, p=.011, d=0.37$, and the crime focused version $(M=5.67, \mathrm{SD}=1.29)$, although the latter difference did not reach standard conventional level of significance, $t(189.87)=1.86, p=.064, d=0.27$. Similarly, differences between severity ratings of the offender focused and the crime focused scenario versions were also not significant, $t(190.14)=0.52, p=.602, d=0.07$. We submitted participants' ratings of the severity of the scenarios to an ANOVA with scenario

\footnotetext{
3 As the sample included several participants who were deemed to be very fast and thus potentially inattentive (this is a known drawback of data collection on Amazon Mechanical Turk; Goodman, Cryder, \& Cheema, 2013), we reran all analyses excluding all participants who took less than $27 \mathrm{~s}$ to answer the nine-item direct endorsement rating scale of punishment goals (this means they took less than $3 \mathrm{~s}$ for each question) and less than $9 \mathrm{~s}$ for the indirect reaction measure of punishment goals (this means they took less than $3 \mathrm{~s}$ to read each potential reaction). The sample size without these individuals was $N=257$. Although we found minor differences in the data, the general pattern and conclusions were identical.
} 
version (crime focused, offender focused, and community focused) as the betweensubjects factor; this indicated significant differences between scenario versions, $F(2$, $288)=3.27, p=.039, \hat{\eta}_{\mathrm{G}}^{2}=.022$. Importantly, however, the perceived severity of a crime is known to be associated with more retributive punishment (Gromet \& Darley, 2006). Thus, since we predicted an association of the salience of communityrelated information with general prevention as the main punishment goal (rather than retribution), these differences would actually work against our hypotheses.

Furthermore, the perceived stability of the cause of the crime differed between the three scenarios, with an attribution to less stable causes in the crime focused version $(M=3.70, \mathrm{SD}=1.72)$ than in the offender focused $(M=4.22, \mathrm{SD}=1.52)$, $t(192.10)=-2.24, p=.026, d=-0.32$, and the community focused versions $(M=4.52, \mathrm{SD}=1.58), t(191.70)=-3.45, p<.001, d=-0.50$. There were no significant differences between the offender focused and the community focused scenario versions, $t(189.31)=1.33, p=.184, d=0.19$. We submitted participants' ratings of the stability of the cause of the crime to an ANOVA with scenario version (crime focused, offender focused, and community focused) as between-subjects factor; this indicated significant differences between scenario versions, $F(2,288)=6.44$, $p=.002, \hat{\eta}_{\mathrm{G}}^{2}=.043$. Importantly, the perceived instability of the cause of a crime is known to be associated with a more special preventive punishment (Weiner et al., 1997). Thus, since the burglary is attributed to less stable causes in the crime focused version (and not in the offender focused version), these differences would also work against our hypotheses: We predicted an association of the salience of offender-related information with special prevention as the punishment goal. In terms of the perceived controllability of the cause of the crime, we found no differences between the scenario versions, replicating the results of our first preliminary study. In particular, the burglary in the crime focused scenario $(M=6.11, \mathrm{SD}=1.26)$ was rated as equally controllable as in the offender focused $(M=6.06, \mathrm{SD}=1.26)$, $t(193.94)=0.27, p=.785, d=0.04$, and the community focused scenario versions $(M=6.16, \mathrm{SD}=1.10), t(190.44)=0.28, p=.783, d=0.04$. Differences between the offender focused and the community focused scenario versions were also not significant, $t(187.82)=0.56, p=.574, d=0.08$. We submitted participants' ratings of the controllability of the cause of the crime to an ANOVA with scenario version (crime focused, offender focused, and community focused) as the between-subjects factor; this confirmed that there were no significant differences between scenario versions, $F(2,288)=0.15, p=.860, \hat{\eta}_{\mathrm{G}}^{2}=.001$.

\section{Indirect Measure: Choice of Reaction}

As an indirect measure of the primary punishment goal participants intended to achieve, we asked them to select one of the three possible reactions to the burglary. Each reaction primarily reflected one punishment goal (as pretested in the second preliminary study). Figure 1 displays the choice frequency of each reaction per condition. In line with our hypotheses, the retributive reaction was selected most often by participants in the crime focused condition, the special preventive reaction was selected most often in the offender focused condition, and the general preventive reaction was selected most often in the community focused condition. To analyze 


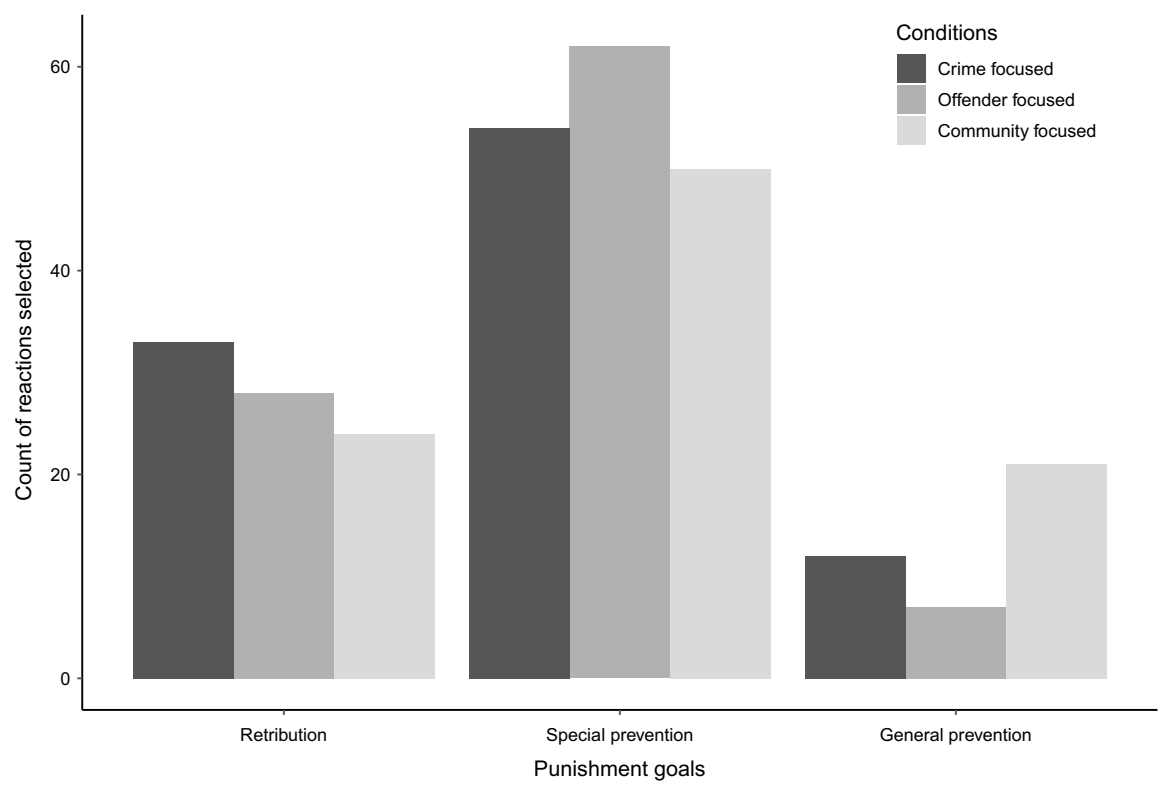

Fig. 1 Punishment goals are reflected by the reactions participants could choose from. Presented is the number of times a reaction was selected depending on the condition

the association between the focus of the scenario and the reaction chosen, we conducted a Chi-square test of independence. There was a significant association between the focus of the scenario and the reaction chosen, $\chi^{2}(4)=10.35, p=.035$. To break down this association, one can inspect the standardized residuals; however, this indicated only significantly more general preventive reactions selected in the community focused condition, but no further differences.

\section{Direct Measure: Endorsement of Punishment Goals}

Correlations and internal consistencies of the three scales measuring the endorsement of punishment goals, as well as their descriptive statistics, are summarized in Table 1 . To statistically compare individuals' endorsement of the three punishment goals across conditions, we first calculated a mixed-design ANOVA with the specific punishment goal (retribution, special prevention, and general prevention) as the within-subjects factor and the condition (crime focused, offender focused, and community focused) as the between-subjects factor, followed by pairwise post hoc $t$-tests. ${ }^{4}$

The overall ANOVA indicated significant main effects of the condition, $F(2,288)=5.95, p=.003, \hat{\eta}_{\mathrm{G}}^{2}=.03$, and the punishment goal to be rated, $F(2$, $576)=27.77, p<.001, \hat{\eta}_{\mathrm{G}}^{2}=.03$, with special prevention being the most endorsed

\footnotetext{
${ }^{4}$ We conducted Welsh's $t$-test to adjust for unequal variances between groups.
} 
Table 1 Table with all means and standard deviations of the endorsement of punishment goals, as well as Cronbach's alphas and factor inter-correlations

\begin{tabular}{|c|c|c|c|c|c|c|c|}
\hline \multirow[t]{2}{*}{ Punishment goal } & \multirow{2}{*}{$\begin{array}{l}\text { Overall } \\
M(\mathrm{SD})\end{array}$} & \multirow{2}{*}{ 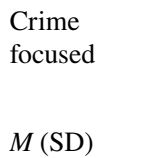 } & \multirow{2}{*}{$\begin{array}{l}\text { Offender } \\
\text { focused } \\
M(\mathrm{SD})\end{array}$} & \multirow{2}{*}{$\begin{array}{l}\text { Community } \\
\text { focused } \\
M(\mathrm{SD})\end{array}$} & \multicolumn{3}{|c|}{$\begin{array}{l}\text { Correlations \& } \\
\text { internal consisten- } \\
\text { cies }\end{array}$} \\
\hline & & & & & (1) & (2) & (3) \\
\hline (1) Retribution & $5.48(1.26)$ & $5.60(1.15)$ & $5.19(1.26)$ & $5.65(1.32)$ & $(.85)$ & & \\
\hline $\begin{array}{l}\text { (2) Special } \\
\text { prevention }\end{array}$ & $5.95(0.93)$ & $5.91(0.84)$ & $5.86(1.06)$ & $6.07(0.88)$ & .40 & $(.43)$ & \\
\hline $\begin{array}{l}\text { (3) General } \\
\text { prevention }\end{array}$ & $5.84(1.19)$ & $5.86(1.06)$ & $5.49(1.32)$ & $6.17(1.08)$ & .68 & .45 & $(.85)$ \\
\hline
\end{tabular}

Higher values indicate a higher endorsement of the punishment goal in the respective crime situation. The three scales' Cronbach's alphas are displayed in brackets in the diagonal of the right part of the table describing the correlations and internal consistencies of the scales

goal of punishment. Most importantly, the interaction between support for different punishment goals and the salience of different aspects of the burglary was significant, $F(4,576)=2.85, p=.023, \hat{\eta}_{\mathrm{G}}^{2}=.01$. However, follow-up $t$-tests directly examining our hypotheses yielded mixed results. According to our hypotheses, retribution should have been deemed as most important in the crime focused condition; however, this was not the case. Whereas retribution was rated more important in the crime focused condition than in the offender focused condition, $t(191.38)=2.36$, $p=.010, d=0.34$, there were no differences to the community focused condition, $t(185.94)=-0.30, p=.618, d=-0.04 .^{5}$ Special prevention should have been rated most important in the offender focused condition. This was also not the case since there were no statistically significant differences between the offender focused and crime focused conditions, $t(182.59)=-0.42, p=.661, d=-0.06$, and the offender focused and community focused conditions, $t(185.06)=-1.53, p=.936$, $d=-0.22$. In fact, these differences were not only nonsignificant; they also showed a descriptive trend in the opposite direction of the one predicted by the hypotheses. In line with our hypotheses, general prevention was rated as most important in the community focused condition; there were significant differences to ratings of general prevention in the offender focused condition, $t(184.26)=3.92, p<.001$, $d=0.57$, and the crime focused condition, $t(191.24)=2.05, p=.021, d=0.29$.

\section{Discussion}

In this experiment, participants indicated their reaction to a scenario about a burglary. In the scenario, we manipulated the salience of information about the crime, the offender, or the community in which the crime occurred. Subsequently, we indirectly (i.e., through a forced choice reaction item) and directly

\footnotetext{
5 We report negative $d$-values whenever the observed effect is in the opposite direction of the one predicted by the hypotheses.
} 
(i.e., through an endorsement rating measure) measured participants' punishment goals. Overall, we found mixed results with inconsistencies between the direct and indirect measures of punishment goals. There was no strong support for our hypotheses in the direct endorsement measure of punishment goals (i.e., by simply asking participants to indicate their endorsement of different punishment goals on a rating scale). In fact, participants strongly endorsed all three punishment goals independent of the experimental condition, with both preventive punishment goals actually turning out to be more popular than retribution. This is in line with research suggesting that individuals are largely unaware of their punishment goals and particularly overestimate the influence of utilitarian goals on their own punishment decisions (Carlsmith, 2008; Crockett et al., 2014). Additionally, the internal consistency of the three items measuring the endorsement of special prevention was rather low (Cronbach's alpha $=.43$ ), further increasing skepticism about the interpretability of this approach to measure laypeople's punishment goals extracted from the literature.

Measuring participants' punishment goals in a more indirect manner revealed a general pattern that was consistent with our hypotheses. Specifically, the retributive reaction was selected most often by participants in the crime focused condition; the special preventive reaction was selected most often by participants in the offender focused condition; and the general preventive reaction was selected most often by participants in the community focused condition. However, although we found the anticipated patterns, there was insufficient statistical power to detect statistically significant differences in the corresponding pairwise comparisons, as the a priori power analysis was based on the overall significance test (a Chi-square test of independence, which was indeed significant) rather than on the subsequent pairwise comparisons.

Based on these results, we attempted to shed further light on the appropriateness of the hypotheses in a second experiment. Specifically, we designed a within-subjects experiment to increase statistical power and recruited participants from other online platforms to decrease the risk of inattentive participants (Goodman et al., 2013). Additionally, we solely employed an indirect measure of punishment goals, given that the interpretation of the direct measure turned out to be rather difficult in our first experiment, as was also the case in previous research (Carlsmith, 2008; Crockett et al., 2014). Specifically, we modified the indirect reaction measure from Experiment 1 to a rating scale, asking participants to rate how appropriate the reactions were as a response to different offenses described in scenarios with varying aspects of the crime situation being salient. 


\section{Experiment 2}

\section{Methods}

\section{Measures and Procedure}

After providing informed consent and demographic information, participants read five scenarios about different crimes that were presented in randomized order: all three versions of the scenario about the burglary from Experiment 1 and two new scenarios (one describing a carjacking and one describing an armed assault). These additional scenarios were added in order to prevent a response bias due to a perceived 'fit' between the three reactions and the three scenarios. Importantly, one of these new scenarios served as an attention check (i.e., it consisted of an instruction to answer the following questions in a specified way). After each scenario, participants were asked to rate the appropriateness of all three punishment reactions. As in the first experiment, these punishment reactions were extracted from our second preliminary study to indirectly measure participants' punishment goals (i.e., they were the same as in Experiment 1). However, we changed the dependent variable from a forced choice item (i.e., participants select one of the three reactions) to an appropriateness rating of each of the three reactions ('How appropriate do you think this reaction is to what was described in the article?'). This gives the possibility of using more powerful statistical tests including more advantageous follow-up comparisons, while retaining the indirect nature of measuring punishment goals. Each reaction was rated on a 7-point scale ranging from $1=$ 'Barely better than no reaction' to $7=$ 'Could not imagine a better reaction.' Higher values indicate a higher perceived appropriateness of the punishment reaction in the respective crime situation. Participants were then asked to respond to several comprehension questions and a singleitem attention check before they were debriefed and thanked.

\section{Sample}

A pragmatic approach was utilized to determine sample size prior to data collection, with a threshold of at least 120 participants, after exclusion of inattentive participants. Data collection had a planned cessation after a 1-month period, but only if the threshold was reached. Participants were recruited through personal contacts, social media platforms, and mailing lists. By the end of our survey period on September 21, 2017, data from $N=461$ participants were available. From these participants, $n=1$ had to be excluded because consent was withdrawn after participation. Furthermore, $n=94$ participants had to be excluded because they answered the attention check question at the end of the experiment incorrectly, leaving a sample of $N=366$ participants. ${ }^{6}$ According to a post hoc power analysis conducted with G*Power (Faul

\footnotetext{
${ }^{6}$ Unfortunately, $n=176$ participants from our final sample did not answer the attention check filler scenario correctly (i.e., they did not answer the questions following this scenario in the instructed way). However, this may have been caused by a somewhat ambiguous instruction for this scenario, as indicated by a few private comments during data collection. The sample size without these individuals was
} 
Table 2 Table with all means and standard deviations of the appropriateness of the three punishment reactions, depending on the condition

\begin{tabular}{lllll}
\hline Punishment goal & Overall & Crime focused & Offender focused & $\begin{array}{l}\text { Community } \\
\text { focused } \\
M(\mathrm{SD})\end{array}$ \\
& $M(\mathrm{SD})$ & $M(\mathrm{SD})$ & $M(\mathrm{SD})$ & $M .82(1.72)$ \\
\hline Retributive reaction & $3.94(1.84)$ & $4.45(1.84)$ & $3.54(1.84)$ & $4.57(1.82)$ \\
Special preventive reaction & $4.67(1.83)$ & $4.38(1.79)$ & $5.06(1.81)$ & $4.24(1.92)$ \\
General preventive reaction & $3.73(1.86)$ & $3.72(1.78)$ & $3.22(1.73)$ & \\
\hline
\end{tabular}

Higher values indicate a higher appropriateness of the punishment reaction in the respective crime situation

et al., 2009), this results in a power of .98 to detect an effect of $f=.175$ (small to medium effect size) in a repeated measures ANOVA $(\alpha=.05$, number of groups $=3$, number of measurements $=3$, and nonsphericity correction $\epsilon=1)$. In the final sample, ages ranged between 18 and 74 years $(M=25.78, \mathrm{SD}=11.29)$ and $73 \%$ of participants were female. The majority of participants indicated they were of Caucasian ethnicity (61\%), fluent in English (83\%), and located in the USA (72\%).

\section{Results}

The descriptive statistics with the overall means and standard deviations of the appropriateness ratings of the three punishment reactions are reported in Table 2. To statistically compare individuals' appropriateness ratings of the three punishment reactions across conditions, we submitted participants' appropriateness ratings of the three punishment reactions to a repeated measures ANOVA with both the condition (crime focused, offender focused, and community focused) and the punishment reaction achieving a particular goal (retribution, special prevention, and general prevention) as within-subjects factors, followed by pairwise post hoc $t$-tests. The analysis of variance revealed a significant, but very small, main effect of the focus of the scenario, $F(2,730)=20.20, p<.001, \hat{\eta}_{\mathrm{G}}^{2}=.004$, and a main effect of the punishment reaction, $F(2,730)=45.46, p<.001, \hat{\eta}_{\mathrm{G}}^{2}=.05$, with the special preventive reaction being more popular than both the retributive and general preventive reactions. Most importantly, we found a significant interaction between the focus of the scenario and the appropriateness of the punishment reactions rated, $F(4,1460)=60.47, p<.001$, $\hat{\eta}_{\mathrm{G}}^{2}=.04$.

Follow-up $t$-tests that directly examined our predictions revealed results that were in line with our hypotheses (and the patterns of the indirect reaction measure of punishment goals from Experiment 1): As such, the retributive reaction was rated as significantly more appropriate in the crime focused condition than

Footnote 6 (continued)

$N=190$. We also conducted our main analyses excluding these participants. Although we found minor differences in the data, the general pattern and conclusions were identical. 


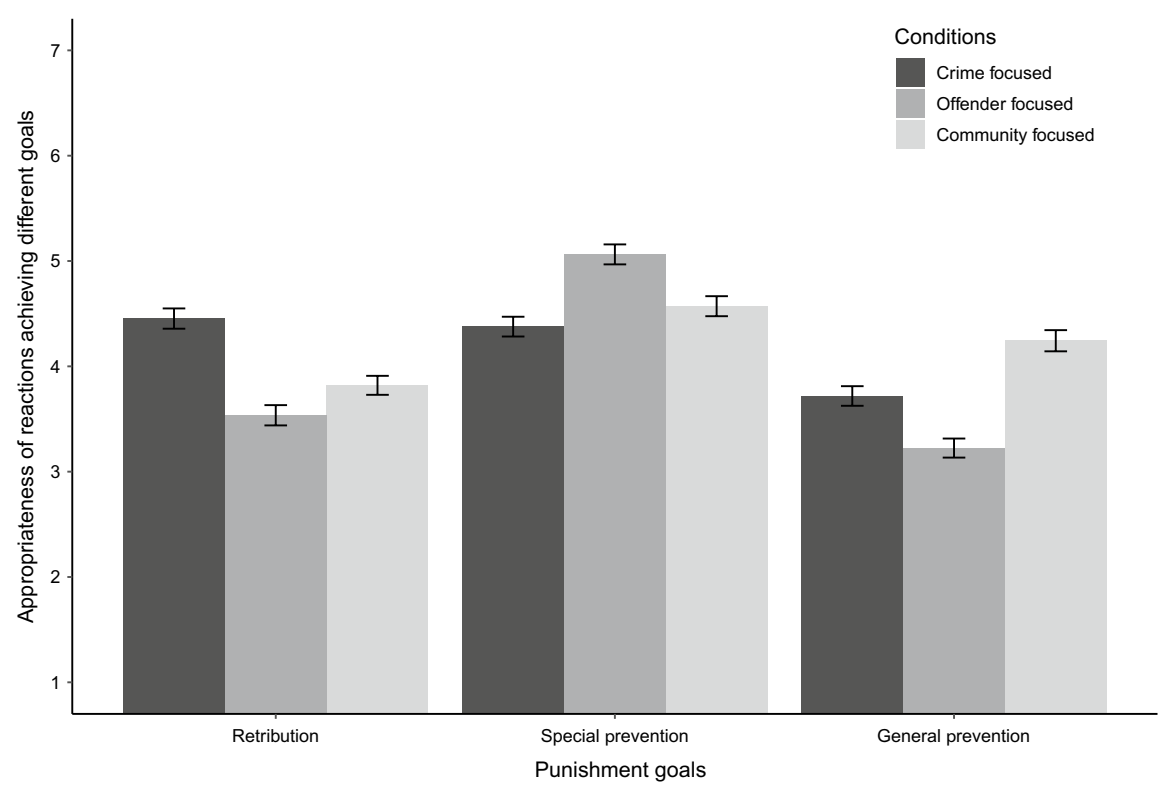

Fig. 2 Ratings of the appropriateness of the three reactions achieving different punishment goals depending on the condition. Error bars represent one standard error of the mean

in the offender focused condition, $t(365)=9.21, p<.001, d=0.48$, and the community focused condition, $t(365)=7.73, p<.001, d=0.40$. Furthermore, as predicted, the special preventive reaction was rated as significantly more appropriate in the offender focused condition than in the crime focused condition, $t(365)=7.72$, $p<.001, d=0.40$, and the community focused condition, $t(365)=5.13, p<.001$, $d=0.27$. Finally, the general preventive reaction was rated as significantly more appropriate in the community focused condition than in the crime focused condition, $t(365)=5.83, p<.001, d=0.30$, and the offender focused condition, $t(365)=9.83$, $p<.001, d=0.51$. Figure 2 gives an overview of these results.

\section{Discussion}

In this experiment, participants indicated their punishment goals by rating the appropriateness of different reactions to (scenarios about) crimes. In the scenarios, we manipulated the salience of specific information about the crime, the offender, or the community in which the crime occurred. As predicted, there was an association of the salience of information and the punishment goals participants intended to achieve. Specifically, we found that in a crime situation in which all punishment goals are eligible in principle, retribution was rated as most appropriate when information about the crime itself was salient, special prevention was rated as most appropriate when information about the offender was salient, and general prevention was rated as most appropriate when information about the community the crime occurred in was salient. 


\section{General Discussion}

Most literature on punishment goals suggests that laypeople's punishment intentions are best described as primarily retributive, rather than occurring for utilitarian purposes such as special prevention or general prevention; this has fostered the belief that 'people are intuitive retributivists' (Carlsmith \& Darley, 2008, p. 211; see also Carlsmith, 2006; Carlsmith et al., 2002; Giacomantonio \& Pierro, 2014; Goodwin \& Gromet, 2014; Keller et al., 2010). However, there is a growing body of evidence suggesting that laypeople's punishment goals are context dependent and influenced by a variety of factors (e.g., Giacomantonio \& Pierro, 2014; Giacomantonio et al., 2017; Weiner et al., 1997). The present research adds to this by investigating the influence of information salient about a crime situation on laypeople's punishment goals. Accordingly, in two preregistered experiments applying both a betweensubjects design and within-subjects design, we gave participants a description of a crime situation in which all punishment goals are eligible in principle, but manipulated the salience of specific aspects in the description of this situation: the offender, the community in which the crime occurred, and the crime itself. Participants were asked to choose from (Experiment 1) or rate the appropriateness of (Experiment 2) different reactions to the crime situation; these reactions were pretested for the degree to which they served each of the punishment goals: special prevention, general prevention, and retribution. As hypothesized, we found that participants' punishment goals were associated with the salience of specific aspects of the crime situation. More specifically, (1) the special preventive reaction was more likely to be selected and rated as more appropriate when information about the offender of the crime was salient. In turn, (2) the general preventive reaction was more likely to be selected and rated as more appropriate when information about the community the crime occurred in was salient. Finally, (3) the retributive reaction was more likely to be selected and rated as more appropriate when information about the crime itself was salient.

Although we found this fairly clear pattern of results when indirectly measuring participants' punishment goals, the results were more mixed for a direct endorsement rating measure (in Experiment 1): There was no evidence for retribution and special prevention as punishment goals, that is, retribution and special prevention were rated as equally important no matter which information of the crime was salient. However, we only found the expected association for general prevention, which was rated as more important in the community focused condition than in the crime focused and the offender focused conditions. These somewhat mixed results may have been caused by unintended differences between the conditions regarding the perceived stability of the cause of the crime and the perceived severity of the misbehavior in Experiment 1, as indicated on the control variables. These differences worked against our hypotheses and thus made our tests more conservative (i.e., it was more difficult to detect the expected effects). Nonetheless, we found patterns complementing our hypotheses for the second dependent variable by measuring participants' punishment goals with a more indirect approach. We therefore 
deem the resulted patterns as interpretable despite the unexpected differences complicating the detection of the effects.

The mixed results found in Experiment 1 may also be due to general problems in measuring participants' endorsement of punishment goals by directly asking them to indicate the motivations underlying their punishment behavior, a problem that has already been documented in past research (e.g., Crockett et al., 2014). In fact, our participants indicated that they strongly endorsed all three punishment goals, leading to an overall ceiling effect of endorsement that has also been observed in past work (Carlsmith, 2008). This corroborates the previous conclusion that people are largely unaware of their punishment goals and particularly overestimate the influence of utilitarian goals on their own punishment decisions, which results in weak correlations of introspective self-ratings on punishment goals and actual punishment behavior (Applegate, Cullen, Turner, \& Sundt, 1996; Carlsmith, 2008; Crockett et al., 2014).

Such differences between people's stated and actually pursued punishment goals beg the question whether both approaches (i.e., direct and indirect measures) actually target the very same construct. If so, one may ask which is the more valid way of measurement. If not, one may ask which constructs are actually represented in such measures, as this may have far-reaching implications for prior and future research using such approaches. In any case, our results corroborate past evidence (Carlsmith, 2008), suggesting two rather different representations of punishment goals that do not necessarily correlate perfectly. That is, as also shown in other domains of research in morality and justice-related decision-making, it appears that people fundamentally differ in their abstract versus concrete ways of thinking (Nichols $\&$ Knobe, 2007). In the context of punishment, people are consistently more willing to support utilitarian purposes when thinking in the abstract, whereas they are more willing to support retribution when it comes to a concrete case of punishment. Future research may further scrutinize the differences between punishment goals in abstract versus concrete situations of misbehavior, for example, by using the continuous indirect measure of people's punishment goals we applied in Experiment 2, along with a direct measure (e.g., the one we applied in Experiment 1).

On a substantive level, our results confirm that the focus inherent in the description of a specific crime situation has an influence on laypeople's punishment goals. This also adds to research raising awareness about how the methodological approaches used to study punishment goals in the past may have influenced researchers' assessment of the motivational basis of laypeople's punishment (e.g., Goodwin $\&$ Benforado, 2015). Consequently, the present research supports the development of using more diverse methodological approaches to study the underlying motivational basis of punishment behavior, such as economic games (Crockett et al., 2014) or scenario studies about the punishment of animals (Goodwin \& Benforado, 2015). In addition, there is research applying more indirect approaches such as the information selection paradigm (Carlsmith, 2006; Keller et al., 2010). In these studies, participants received minimal information about a crime and were asked to make a punishment decision. Prior to their decision, they were given the chance to ask questions about the crime context. It has been shown that individuals were primarily interested in aspects of the crime itself (e.g., the magnitude of harm) rather than 
other aspects of the crime situation (e.g., information about the offender). Hence, laypeople actively search for retribution-associated aspects rather than factors that are associated with utilitarian punishment and therefore may 'intuitively' focus on the crime itself when asked to propose a punishment.

Nonetheless, our findings suggest that if people's attention is drawn to other aspects of the crime situation (e.g., the offender's motives or the community in which the crime occurred), they are able to incorporate this information into their decision-making and consider potential secondary (i.e., utilitarian) effects of their punishment behavior, if appropriate. However, if this information is not salient, individuals tend to focus on a backward-oriented, retributive punishment, without considering potential long-term effects of their decision-making (Baron \& Ritov, 2009; McCaffery \& Baron, 2006). This is also in line with studies showing that people's punishment goals shift once they are explicitly told to focus on a specific target of the crime situation (Gromet \& Darley, 2009). Importantly, the present research goes beyond these insights as we applied a more subtle experimental manipulation by varying the salience of the presumably relevant aspects of the scenario describing a crime situation within the material itself, rather than providing explicit instructions to participants.

Thus, our results may be a next step to understanding the processes underlying individuals' punishment behavior, suggesting that it strongly depends on the information environment as has been argued and found in many other domains of judgment and decision-making (e.g., Fiedler, 2000, 2008). In any case, further research is needed to explore the processes of punishment decision-making. For example, future research may apply more enriched methodological approaches (e.g., eye tracking) to investigate which features of a crime situation are naturally most relevant for a punishment decision and, hence, become more salient to punishers which may drive their punishment goals and preferences.

In both studies, we also found a general overall preference for a special preventive reaction to the criminal situation across conditions. This is surprising at first glance, since it contrasts with most research suggesting retribution as the primary goal of individuals' punishment. However, it may be attributed to the general structure and content of our material, that is, the intended equivalence across conditions: We created the material to be equivalent regarding the perceived severity of the crime and the attribution of the criminal behavior described in the scenario in terms of the controllability and stability of the cause of the criminal behavior. Additionally, the scenarios were created to ensure that all three punishment goals are eligible in principle, that is, if one carefully considers all information of the crime situation, all punishment goals should be highly supported. To achieve this, we chose a crime scenario in which participants were likely to attribute the misbehavior to rather unstable causes. Prior research has already shown that this attribution results in stronger endorsement of special prevention as a punishment goal (Weiner et al., 1997) and thus can explain the general preference for special prevention in our findings.

It should be acknowledged that we only focused on one specific crime situation, a burglary, which was detailed in a very particular way (e.g., providing mitigating circumstances for the offender's behavior). Therefore, we cannot generalize the effects of information salience on punishment goals demonstrated in our research 
as applicable to all scenarios describing crimes. Indeed, this also depends on the particular aspects of the crime situation itself, such as attributional processes or the magnitude of harm. By focusing on a specific type of crime, we aimed to increase the consistency of the perceived severity of the misbehavior, as well as the attribution of it (as also assured through extensive pretesting of the materials used), since this has already been shown to affect people's punishment goals (Gromet \& Darley, 2006; Weiner et al., 1997). Given the association of crime severity, attributional processes, and punishment goals, future research may investigate whether information salience can also influence laypeople's punishment goals for less or more severe crimes that are attributed differently in terms of the stability and controllability its cause. For example, one may speculate that it is much more difficult to direct people's attention to other aspects of the crime situation (e.g., the community) when the offense is of extreme severity, such as rape or murder. Furthermore, it is presumably unlikely to make people aim for rather long-term, future-oriented effects of punishment decisions (e.g., special prevention) if the information about the offender portrays them as intrinsically malicious.

Relatedly, by manipulating the salience of specific aspects of the crime situation, we provided participants with additional information that differed across conditions. This may arguably imply the limitation that the content of this additional information, rather than the salience of crime aspects, may have driven the results. Importantly, however, we carefully created and pretested all materials to rule out such a threat to the validity of our results. As such, all scenario versions consisted of a main paragraph providing participants with basic information about the crime, the offender, and the community. Although each condition also consisted of a second paragraph making specific aspects of the crime situation more salient, this did not add any information to different scenario conditions that may have influenced the perception of the crime situation on dimensions known to be associated with people's punishment goals (as shown in the second preliminary study). Consequently, we are confident in the interpretation that the results yielded provide further evidence for the suggested association of information salience and laypeople's punishment goals.

Finally, the results of the present research also raise questions about the importance of other punishment goals. One increasingly discussed punishment goal is that of restorative justice, which attempts to restore the victim, reintegrate the offender, and repair the harm that has been caused to the community by the misbehavior (Gromet \& Darley, 2006). One key element of restorative justice processes is a faceto-face meeting involving all parties: the victim, the offender, and other community members. In this meeting, the offender and the victim present their perspectives on the misbehavior and using a consensus decision-making approach, work out an appropriate punishment for the offender with participation from all parties (this usually involves an apology, a monetary compensation, community services, and the like). As the perspective and voice of the victim are an important factor for restorative punishment, the salience of this aspect could have an influence on laypeople's support for this punishment goal. However, as the offender's and the community's perspectives are also considered in restorative punishment processes, research is 
needed to investigate which aspects are particularly important for this punishment goal and thus may be highlighted to make people strive for restorative justice.

In conclusion, our research confirms that laypeople's support for different punishment goals is affected by the salience of different aspects of an article describing a crime situation. That is, if information about the crime situation focuses on aspects other than the crime itself, people consider this information in their decision-making process and, if appropriate, pay greater attention to achieving more utilitarian goals with their punishment. In other words, laypeople are not able to consider utilitarian punishment goals if they receive no information about the need for, nor the usefulness of potential future-oriented punishment reactions; such relevant information needs to be salient in order to enable an equal chance for utilitarian (vs. retributive) punishment to be adequately considered.

Acknowledgements Open Access funding provided by Projekt DEAL. The first author was supported by the research training group UpGrade, funded by the German Research Foundation (DFG; GRK No GK1561/2). The second author received funding from Mitacs RISE-Globalink Research Internship, German Academic Exchange Service (DAAD), and the DFG.

Author Contributions All authors designed the experiments; MT and KTT collected data; MT analyzed the data with help from KTT and BEH; and MT wrote the manuscript with critical edits from KTT and BEH.

\section{Compliance with Ethical Standards}

Ethical Approval All procedures performed in studies involving human participants were in accordance with the ethical standards of the institutional and/or national research committee and with the $1964 \mathrm{Hel}-$ sinki Declaration and its later amendments or comparable ethical standards.

Open Access This article is licensed under a Creative Commons Attribution 4.0 International License, which permits use, sharing, adaptation, distribution and reproduction in any medium or format, as long as you give appropriate credit to the original author(s) and the source, provide a link to the Creative Commons licence, and indicate if changes were made. The images or other third party material in this article are included in the article's Creative Commons licence, unless indicated otherwise in a credit line to the material. If material is not included in the article's Creative Commons licence and your intended use is not permitted by statutory regulation or exceeds the permitted use, you will need to obtain permission directly from the copyright holder. To view a copy of this licence, visit http://creativecommons.org/licen ses/by/4.0/.

\section{References}

Aharoni, E., Kleider-Offutt, H. M., Brosnan, S. F., \& Watzek, J. (2018). Justice at any cost? The impact of cost/benefit salience on criminal punishment judgments. Behavioral Sciences \& the Law, 37(1), 38-60. https://doi.org/10.1002/bsl.2388.

Applegate, B. K., Cullen, F. T., Turner, M. G., \& Sundt, J. L. (1996). Assessing public support for threestrikes-and-you're-out laws: Global versus specific attitudes. Crime \& Delinquency, 42(4), 517-534. https://doi.org/10.1177/0011128796042004002.

Baron, J., \& Ritov, I. (2009). The role of probability of detection in judgements of punishment. Journal of Legal Analysis, 1(2), 553-590. https://doi.org/10.1093/jla/1.2.553. 
Bentham, J. (1962). Principles of penal law. In J. Bowring (Ed.), The works of Jeremy Bentham (p. 396). Edinburgh: William Tait.

Carlsmith, K. M. (2006). The roles of retribution and utility in determining punishment. Journal of Experimental Social Psychology, 42(4), 437-451. https://doi.org/10.1016/j.jesp.2005.06.007.

Carlsmith, K. M. (2008). On justifying punishment: The discrepancy between words and actions. Social Justice Research, 21(2), 119-137. https://doi.org/10.1007/s11211-008-0068-X.

Carlsmith, K. M., \& Darley, J. M. (2008). Psychological aspects of retributive justice. Advances in Experimental Social Psychology, 40(7), 193-236. https://doi.org/10.1016/S0065-2601(07)00004-4.

Carlsmith, K. M., Darley, J. M., \& Robinson, P. H. (2002). Why do we punish? Deterrence and just deserts as motives for punishment. Journal of Personality and Social Psychology, 83(2), 284-299. https://doi.org/10.1037//0022-3514.83.2.284.

Crockett, M. J., Özdemir, Y., \& Fehr, E. (2014). The value of vengeance and the demand for deterrence. Journal of Experimental Psychology: General, 143(6), 2279-2286. https://doi.org/10.1037/xge00 00018.

Faul, F., Erdfelder, E., Buchner, A., \& Lang, A.-G. (2009). Statistical power analyses using G*Power 3.1: Tests for correlation and regression analyses. Behavior Research Methods, 41(4), 1149-1160. https ://doi.org/10.3758/BRM.41.4.1149.

Fehr, E., \& Fischbacher, U. (2004). Third-party punishment and social norms. Evolution and Human Behavior, 25(2), 63-87. https://doi.org/10.1016/S1090-5138(04)00005-4.

Fiedler, K. (2000). Beware of samples! A cognitive-ecological sampling approach to judgment biases. Psychological Review, 107(4), 659-676. https://doi.org/10.1037/0033-295X.107.4.659.

Fiedler, K. (2008). The ultimate sampling dilemma in experience-based decision making. Journal of Experimental Psychology: Learning, Memory, and Cognition, 34(1), 186-203. https://doi. org/10.1037/0278-7393.34.1.186.

Giacomantonio, M., \& Pierro, A. (2014). Individual differences underlying punishment motivation the role of need for cognitive closure. Social Psychology, 45(6), 449-457. https://doi.org/10.1027/18649335/a000211.

Giacomantonio, M., Pierro, A., Baldner, C., \& Kruglanski, A. (2017). Need for closure, torture, and punishment motivations: The mediating role of moral foundations. Social Psychology, 48(6), 335-347. https://doi.org/10.1027/1864-9335/a000321.

Goodman, J. K., Cryder, C. E., \& Cheema, A. (2013). Data collection in a flat world: The strengths and weaknesses of Mechanical Turk samples. Journal of Behavioral Decision Making, 26(3), 213-224. https://doi.org/10.1002/bdm.1753.

Goodwin, G. P., \& Benforado, A. (2015). Judging the goring ox: Retribution directed toward animals. Cognitive Science, 39(3), 619-646. https://doi.org/10.1111/cogs.12175.

Goodwin, G. P., \& Gromet, D. M. (2014). Punishment. Wiley Interdisciplinary Reviews: Cognitive Science, 5(5), 561-572. https://doi.org/10.1002/wcs.1301.

Gromet, D. M., \& Darley, J. M. (2006). Restoration and retribution: How including retributive components affects the acceptability of restorative justice procedures. Social Justice Research, 19(4), 395432. https://doi.org/10.1007/s11211-006-0023-7.

Gromet, D. M., \& Darley, J. M. (2009). Punishment and beyond: Achieving justice through the satisfaction of multiple goals. Law and Society Review, 43(1), 1-38. https://doi.org/10.111 1/j.1540-5893.2009.00365.x.

Kant, I. (1952). The science of right (W. Hastie, trans.). In R. M. Hutchins \& M. J. Adler (Eds.), Great books of the western world (pp. 397-446). Edinburgh: Encyclopedia Britannica.

Keller, L. B., Oswald, M. E., Stucki, I., \& Gollwitzer, M. (2010). A closer look at an eye for an eye: Laypersons' punishment decisions are primarily driven by retributive motives. Social Justice Research, 23(2), 99-116. https://doi.org/10.1007/s11211-010-0113-4.

McCaffery, E. J., \& Baron, J. (2006). Isolation effects and the neglect of indirect effects of fiscal policies. Journal of Behavioral Decision Making, 19, 289-302. https://doi.org/10.1002/bdm.525.

Nichols, S., \& Knobe, J. (2007). Moral responsibility and determinism: The cognitive science of folk intuitions. Nous, 41(4), 663-685. https://doi.org/10.1111/j.1468-0068.2007.00666.x.

Orth, U. (2003). Punishment goals of crime victims. Law and Human Behavior, 27(2), 173-186. https:// doi.org/10.1023/A:1022547213760.

Reyna, C., \& Weiner, B. (2001). Justice and utility in the classroom: An attributional analysis of the goals of teachers' punishment and intervention strategies. Journal of Educational Psychology, 93(2), 309319. https://doi.org/10.1037/0022-0663.93.2.309. 
Rucker, D. D., Polifroni, M., Tetlock, P. E., \& Scott, A. L. (2004). On the assignment of punishment: The impact of general-societal threat and the moderating role of severity. Personality and Social Psychology Bulletin, 30(6), 673-684. https://doi.org/10.1177/0146167203262849.

Simmons, J. P., Nelson, L. D., \& Simonsohn, U. (2012). A 21 word solution. Dialogue: The Official Newsletter of the Society for Personality and Social Psychology, 26(2), 4-7. Retrieved from http:// www.ssrn.com/abstract $=2160588$

Tetlock, P. E. (2002). Social functionalist frameworks for judgment and choice: Intuitive politicians, theologians, and prosecutors. Psychological Review, 109(3), 451-471. https://doi. org/10.1037//0033-295X.109.3.451.

Twardawski, M., Hilbig, B. E., \& Thielmann, I. (2020). Punishment goals in classroom interventions: An attributional approach. Journal of Experimental Psychology: Applied, 26(1), 61-72. https://doi. org/10.1037/xap0000223.

Weiner, B., Graham, S., \& Reyna, C. (1997). An attributional examination of retributive versus utilitarian philosophies of punishment. Social Justice Research, 10(4), 431-452. https://doi.org/10.1007/ BF02683293.

Publisher's Note Springer Nature remains neutral with regard to jurisdictional claims in published maps and institutional affiliations. 